\title{
A descriptive study of the prevalence of hypothyroidism among antenatal women and foetal outcome in treated hypothyroid women
}

\author{
Divya R. Prasad*, Neelima V. Nair, Deepika K.
}

Department of Obstetrics and Gynecology, Sree Gokulam Medical College, Venjaramoodu, Trivandrum, Kerala, India

Received: 03 April 2016
Accepted: 07 May 2016

*Correspondence:

Dr. Divya R. Prasad,

E-mail: ms.divanil@rediffmail.com

Copyright: (c) the author(s), publisher and licensee Medip Academy. This is an open-access article distributed under the terms of the Creative Commons Attribution Non-Commercial License, which permits unrestricted non-commercial use, distribution, and reproduction in any medium, provided the original work is properly cited.

\begin{abstract}
Background: The objective of the study was to find out the prevalence of hypothyroidism among pregnant women and to study the foetal outcome in antenatal mothers in whom treatment was initiated early in pregnancy.

Methods: This was a descriptive study conducted in the department of OBG Sree Gokulam Medical College, Venjaramoodu, Trivandrum from April 2013 to Oct 2014. 500 antenatal women coming for routine antenatal check up in the first trimester to antenatal OP were screened for hypothyroidism.TSH(thyroid stimulating hormone) was done in the first trimester and the prevalence of hypothyroidism was estimated. Patients were diagnosed as having subclinical or overt hypothyroidism based on the FT3 (free T3) and FT4 (free T4) results. Patients detected with hypothyroidism -both subclinical and overt were started on appropriate dose of L-thyroxin depending on her gestational age, body weight and level of TSH. Every 6weeks TSH levels were estimated and the dose of the drug adjusted. All these patients were followed up for their foetal outcome such as intrauterine demise, hyperbilirubinemia, prematurity, stillbirths and neonatal hypothyroidism.

Results: In the present study, the prevalence of hypothyroidism was $5.6 \%$ of which $4 \%$ were having subclinical and $1.6 \%$ was having overt hypothyroidism. No significant difference in foetal complications, perinatal mortality and morbidity was noted between hypothyroid and euthyroid women.

Conclusions: TSH testing should be included in routine antenatal investigations for early detection of subclinical and overt hypothyroidism among antenatal women and early treatment should be initiated so as to prevent complications.
\end{abstract}

Keywords: Hypothyroidism, Overt, Subclinical, Foetal outcome

\section{INTRODUCTION}

Thyroid disorders are prevalent in women of child bearing age. Thyroid disorders are the second most common cause of endocrine dysfunction complicating pregnancy. Hypothyroidism is common in pregnancy with an estimated prevalence of $2-3 \%$ for subclinical and $0.3-0.5 \%$ for overt hypothyroidism.

Maternal hypothyroidism is the most common disorder of thyroid function in pregnancy and has been associated with miscarriage, foetal loss, preeclampsia, preterm delivery, abruption, low birth weight, foetal distress and reduced intellectual function of the offspring. ${ }^{1}$ These adverse outcomes have been associated with both overt as well as subclinical hypothyroidism. Overt hypothyroidism is diagnosed when an abnormally high Serum thyrotropin level is accompanied by an abnormally low thyroxin level. Subclinical hypothyroidism is defined as an elevated Serum TSH level and normal Serum thyroxin concentration.

As the foetus does not begin to produce its own thyroid hormones until 12 weeks of gestation, it is solely dependent on circulating maternal thyroid hormone levels, so it is critical that maternal delivery of thyroxin to the foetus is ensured early in gestation. Uncorrected thyroid dysfunction in pregnancy increases the incidence 
of miscarriages, low birth weight, foetal death, and stillbirth. The deleterious effects of thyroid dysfunction can also extend beyond pregnancy and delivery to affect the intellectual development in the early life of the child. Thus any delay in the diagnosis and treatment of hypothyroidism may ultimately result in a progeny with educational, socioeconomic and public health consequences.

The present study was carried out to estimate the prevalence of hypothyroidism among antenatal patients and to initiate early treatment so as to prevent foetal complications.

\section{METHODS}

This was a descriptive longitudinal study, undertaken at Sree Gokulam Medical College (SGMC), Trivandrum. The study was conducted for a period of 18 months from April 2013 to Oct 2014. The study population included 500 consecutive antenatal patients attending OPD.

\section{Inclusion criteria}

- Antenatal patients who are in the first trimester of pregnancy attending antenatal OPD at SGMC.

- Singleton pregnancy.

- Patients already diagnosed with hypothyroidism and on treatment.

\section{Exclusion criteria}

- Diabetes and hypertension.

- Multifoetal gestation.

- Patients who had previous adverse pregnancy outcome with known cause.

500 consecutive new antenatal patients coming to OPD in first trimester of pregnancy for regular antenatal visits were taken for the study. After obtaining informed consent, a detailed history was taken using a structured proforma. Serum TSH testing was done. Hypothyroidism was diagnosed if TSH value was 2.5 or more. If TSH was deranged, then F T3 and F T4 levels were checked. Depending upon FT3 and FT4 levels, they were diagnosed as subclinical or overt hypothyroidism. Thyroxin was started for both groups. Every 6 weeks, TSH levels were estimated and dose of the drug was adjusted. All these women were followed up for their foetal outcome: prematurity, foetal death, stillbirth, neonatal hyperbilirubinemia (cord bilirubin level > 2.5 $\mathrm{mg} / \mathrm{dl}$ ) and congenital hypothyroidism (cord blood TSH and day $3 \mathrm{TSH}$ levels $>20 \mathrm{IU} / \mathrm{ml}$ ).

Data collected was analysed using the statistical software SPSS version 20 with assistance of a statistician. The study variables were checked using appropriate statistical tests (Kruskal-Wallis test, Mann-Whitney test and $\mathrm{p}$ values).

\section{RESULTS}

Table 1: Distribution of study population according to age.

\begin{tabular}{|lll|}
\hline Age (years) & number & Percentage \\
\hline $19-24$ & 222 & 44.4 \\
\hline $25-30$ & 225 & 45 \\
\hline$>30$ & 53 & 10.6 \\
\hline total & 500 & 100 \\
\hline Mean+/-SD & $25.4+/-3.7$ & \\
\hline
\end{tabular}

Table 2: Distribution of study population according to parity.

\begin{tabular}{|lll|}
\hline Age (years) & Frequency & Percentage \\
\hline primi & 226 & 45.2 \\
\hline $2-4$ & 266 & 53.2 \\
\hline$>4$ & 8 & 1.6 \\
\hline total & 500 & 100 \\
\hline
\end{tabular}

Table 3: Prevalence of hypothyroidism.

\begin{tabular}{|lll|}
\hline Hypothyroidism & number & percentage \\
\hline No hypothyroidism & 472 & 94.4 \\
\hline $\begin{array}{l}\text { Subclinical } \\
\text { hypothyroidism }\end{array}$ & 20 & 4 \\
\hline $\begin{array}{l}\text { Overt } \\
\text { hypothyroidism }\end{array}$ & 8 & 1.6 \\
\hline
\end{tabular}

Age: mean age of study population was $25.4+/-3.7$ years (Table 1).

Parity: among 500 patients, 226 (45.2\%) were primigravida, remaining were multigravida (Table 2 ).

Prevalence: the prevalence of hypothyroidism was $5.6 \%$. The prevalence of subclinical hypothyroidism was $4 \%$ and overt hypothyroidism was $1.6 \%$ (Table 3 ).

Association between maternal age and hypothyroidism: Among euthyroid women, the mean age was 25.4+/-3.7 years. The mean age of hypothyroid women was $25.5+/-$ 3.9 years. Among those with hypothyroidism, mean age for subclinical hypothyroidism was 24.9+/-3.9 years and overt hypothyroidism was $26.9+/-3.6$ years (Table 4 ).

Association between parity and hypothyroidism: No statistical difference was seen with respect to parity.

Foetal complications: Complications like foetal death, stillbirth, preterm delivery, neonatal hyperbilirubinemia and congenital hypothyroidism were similar in patients with hypothyroidism who were given treatment and euthyroid patients.

Association between preterm delivery and hypothyroidism: No significant association was observed 
between preterm labour and hypothyroidism. The incidence of preterm labour among patients with subclinical hypothyroidism was $5 \%$ (1) and in those with overt hypothyroidism was $12.5 \%$ (1) and the p value was 0.926 (Table 5).

Table 4: Association between maternal age and hypothyroidism.

\begin{tabular}{|c|c|c|c|c|c|c|c|c|}
\hline \multirow{2}{*}{$\begin{array}{l}\text { Maternal } \\
\text { age(years) }\end{array}$} & \multicolumn{2}{|c|}{$\begin{array}{l}\text { No } \\
\text { hypothyroidism }\end{array}$} & \multicolumn{2}{|c|}{$\begin{array}{l}\text { Subclinical } \\
\text { hypothyroidism }\end{array}$} & \multicolumn{2}{|c|}{$\begin{array}{l}\text { Overt } \\
\text { hypothyroidism }\end{array}$} & \multicolumn{2}{|l|}{ total } \\
\hline & number & $\%$ & number & $\%$ & Number & $\%$ & number & $\%$ \\
\hline $19-24$ & 212 & 95.5 & 8 & 3.6 & 2 & 0.9 & 222 & 100 \\
\hline$>25$ & 260 & 93.5 & 12 & 4.3 & 6 & 2.2 & 278 & 100 \\
\hline total & 472 & & 20 & & 8 & & 500 & 100 \\
\hline Mean+/-SD & $25.4+/-3.7$ & & $24.9+/-3$ & & $26.9+/-3$ & & & \\
\hline
\end{tabular}

Kruskal-Wallis Test $\left(\mathrm{x}^{2}\right)=0.54, \mathrm{p}=0.462$.

Table 5: Association between preterm delivery and hypothyroidism.

\begin{tabular}{|lllllllll|l|}
\hline \multirow{2}{*}{$\begin{array}{l}\text { Preterm } \\
\text { delivery }\end{array}$} & \multicolumn{2}{l}{ No hypothyroidism } & \multicolumn{2}{l}{$\begin{array}{l}\text { Subclinical } \\
\text { hypothyroidism }\end{array}$} & \multicolumn{2}{c|}{ Overt hypothyroidism } & \multicolumn{2}{c|}{ total } \\
& number & $\%$ & number & $\%$ & number & $\%$ & number & $\%$ \\
\hline Absent & 442 & 97.2 & 19 & 95 & 7 & 87.5 & 26 & 92.9 \\
\hline Present & 32 & 2.8 & 1 & 5 & 1 & 12.5 & 2 & 7.1 \\
\hline Total & 472 & 100 & 20 & 100 & 8 & 100 & 28 & 100 \\
\hline
\end{tabular}

Mann-Whitney test $(Z)=0.09, p=0.926$.

Table 6: Association between foetal death/still birth and hypothyroidism.

\begin{tabular}{|c|c|c|c|c|c|c|}
\hline \multirow{2}{*}{$\begin{array}{l}\text { Foetal } \\
\text { death/still } \\
\text { birth }\end{array}$} & \multicolumn{2}{|c|}{ No hypothyroidism } & \multicolumn{2}{|c|}{ Subclinical hypothyroidism } & \multicolumn{2}{|c|}{ Overt hypothyroidism } \\
\hline & number & $\%$ & number & $\%$ & number & $\%$ \\
\hline Absent & 470 & 99.6 & 19 & 95 & 7 & 87.5 \\
\hline Present & 2 & 0.4 & 1 & 5 & 1 & 12.5 \\
\hline Total & 472 & 100 & 20 & 100 & 8 & 100 \\
\hline
\end{tabular}

Mann-Whitney test $(\mathrm{Z})=3.92, \mathrm{p}=0.394$.

Table 7: Association between neonatal hyperbilirubinemia and hypothyroidism.

\begin{tabular}{|lcccc|}
\hline $\begin{array}{l}\text { Neonatal } \\
\text { hyperbilirubinemia }\end{array}$ & No hypothyroidism & \multicolumn{3}{c|}{ hypothyroidism } \\
\hline Absent & 394 & $\%$ & number & $\%$ \\
\hline Present & 78 & 83.5 & 22 & 78.6 \\
\hline Total & 472 & 16.5 & 6 & 21.4 \\
\hline
\end{tabular}

Mann-Whitney test $(\mathrm{Z})=3.92, \mathrm{p}=0.394$.

Association between foetal death/stillbirth and hypothyroidism: In the present study, 5\% (1) of subclinical hypothyroid women and $12.5 \%$ (1) of overt hypothyroid women had foetal death compared to $0.4 \%$ (2) in euthyroid women (Table 6).
Association between neonatal hyperbilirubinemia and hypothyroidism: In the present study, $21.4 \%$ (6) babies with neonatal hyperbilirubinemia were born to hypothyroid mothers compared to $16.5 \%$ (78) babies born to euthyroid women. This is statistically insignificant (Table 7). 
Association between congenital hypothyroidism and hypothyroidism: In this study all babies born to hypothyroid mothers had normal thyroid function as shown by cord blood TSH values (Table 8 ).

Table 8: Association between congenital hypothyroidism and hypothyroidism.

\begin{tabular}{|lcccc|}
\hline \multirow{2}{*}{$\begin{array}{l}\text { Congenital } \\
\text { hypothyroidism }\end{array}$} & \multicolumn{2}{l}{ No } \\
hypothyroidism & \multicolumn{2}{l|}{ nypothyroidism } \\
\cline { 2 - 5 } & number & $\%$ & number & $\%$ \\
\hline Absent & 470 & 99.6 & 28 & 100 \\
\hline Resent & 2 & 0.4 & 0 & 0.0 \\
\hline Total & 472 & 100 & 28 & 100 \\
\hline
\end{tabular}

Mann-Whitney test $(\mathrm{Z})=0.34, \mathrm{p}=0.730$.

\section{DISCUSSION}

During the last 20 years, it has been appreciated that thyroid physiology changes significantly during gestation. Uncorrected thyroid dysfunction in pregnancy has adverse effects on maternal and foetal wellbeing. Thyroid disorders are the second most common endocrinological disorders found in pregnancy with a prevalence of overt hypothyroidism in $0.3-0.5 \%$ of pregnancies and subclinical hypothyroidism in $2-3 \%{ }^{2}$

The present study was done in Sree Gokulam Medical College, Venjaramoodu, Trivandrum. A total of 500 antenatal women were screened for hypothyroidism during the study period of 18 months. This was a descriptive study. The aim of the study was to know the prevalence of hypothyroidism in pregnancy and to know the foetal outcome in treated women.

The mean age of hypothyroid population was 25.5+/-3.9 years. The mean age for subclinical hypothyroidism was 24.9+/-3.9 and overt hypothyroidism was 26.9+/-3.6. Study by Ajmani et al found that maternal age was high in the overt hypothyroid with a mean age of $27.16+/$ 5.237 years. $^{3}$

In our study, among 28 hypothyroid women, 18 (6.5\%) were above 25 years as compared to 10 (4.5\%) women aged less than 25 years. This shows increasing prevalence of hypothyroidism as maternal age advances. In the study of Akhter SN et al, it was observed that $62.1 \%$ of subclinical hypothyroid patients were in the 15-24 years age group and $66.7 \%$ of the overt hypothyroidism patients were in the $25-44$ year age group. ${ }^{1}$

In our study no statistical difference was seen with respect to parity in different groups. A study by Nirmala et al about maternal outcome of hypothyroidism in pregnancy- a south Indian study also showed no statistical difference with respect to parity in different groups. ${ }^{4}$ Unlike the present study, in the study by Akhter $\mathrm{SN}$ et al, it was reported that both subclinical and overt hypothyroidism was predominant in multipara. ${ }^{1}$
Hypothyroidism is a common condition with a prevalence of $0.6-1.6 \%$ in the general population. The prevalence of hypothyroidism in our study was $5.6 \%$ which is comparable with the study by Goel et al in which prevalence of hypothyroidism was $6.3 \% .^{5}$ In the study by Ajmani et al the prevalence of hypothyroidism was $12 \%$ which is higher than our study. ${ }^{3}$ In our study, the prevalence of subclinical hypothyroidism was $4 \%$. This is comparable to the study by Goel et al, where the prevalence of subclinical hypothyroidism was $3.4 \%$. In a study by Goldman $\mathrm{C}$ et al, the prevalence was $2.2 \%$ and another study by Ajmani et al, the prevalence was $9 \%$.,5,6 In a study by Casey BM et al, the prevalence was $23 \%$ which is very high and inconsistent with our study. ${ }^{7}$ In the present study, the prevalence of overt hypothyroidism was $1.6 \%$ which is comparable to the study by Cleary Goldman et al, where the prevalence was less than $1 \%$. In a study by Goel. ${ }^{5,6}$ The prevalence of overt hypothyroidism was $2.9 \%$ and another study by Ajmani et al showed prevalence of 3\%; whereas a study by Sahu MT showed a higher prevalence of $4.58 \%$. $^{2,3}$

In this study, no significant association was observed between preterm labour hypothyroidism. The incidence of preterm labour in subclinical hypothyroidism was $5 \%$ and in overt hypothyroidism was $12.5 \%$. A study conducted by Nirmala et al in Kerala found that preterm labour was seen in $25.6 \%$ of cases and $20.5 \%$ of controls and the difference was not statistically significant. ${ }^{4} \mathrm{~A}$ study by Ajmani et al observed that the incidence of preterm birth in overt hypothyroidism was higher $(33 \%)$ than the present study and in subclinical hypothyroidism, the incidence was $11.2 \%$ compared to euthyroid women. ${ }^{3}$ Casey B M et al found that preterm birth was almost 2 fold higher in women with subclinical hypothyroidism. ${ }^{7}$

In the present study, 5\% subclinical hypothyroid women had foetal death and $12.5 \%$ overt hypothyroidism women had foetal death which is much higher compared to $0.4 \%$ cases in euthyroid women. In a study conducted by Allan WC, Haddow JE et al, the rate of foetal death was significantly higher. Similar findings were observed by Stagnaro Green and associates who found that increased incidence of foetal death with a rate of $17 \%$ among hypothyroid group. ${ }^{8,9}$

In the present study $21.4 \%$ babies with neonatal hyperbilirubinemia were born to hypothyroid women compared to $16.5 \%$ babies born to euthyroid women. This is statistically insignificant. Similar to this study, Ajmani et al observed that the incidence of neonatal hyperbilirubinemia in normal population was $6.1 \%$ in subclinical hypothyroidism and $11.8 \%$ in overt hypothyroidism with no statistical significance. ${ }^{3}$

In our study, all babies born to hypothyroid women had normal thyroid function as shown by cord blood $\mathrm{TSH}$ values. In a study by Akhter SN et al observed a similar finding that none of the babies were hypothyroid as shown by cord blood TSH values. ${ }^{1}$ Similarly Basnet P, 
Aggarwal N, Suri V et al observed that all new born babies had normal thyroid function. ${ }^{10}$

\section{CONCLUSION}

The prevalence of hypothyroidism in our study was $5.6 \%$. Of this, the prevalence of subclinical hypothyroidism was $4 \%$ and that of overt hypothyroidism was $1.6 \%$.

Hypothyroidism during pregnancy was found to be more common among women 25 years or more but the difference was not statistically significant.

No statistical difference with respect to hypothyroidism was noted in different parity groups.

Foetal complications like prematurity, foetal death/stillbirth, neonatal hyperbilirubinemia and congenital hypothyroidism did not show any significant association.

This study concludes that the prevalence of hypothyroidism in pregnancy was significantly high. Subclinical and overt hypothyroidism was prevalent in pregnant women and if detected early will lead to decreased incidence of foetal complications. This emphasises the importance of routine thyroid screening for all antenatal women. Early initiation of treatment and maintenance of abnormal level of thyroid hormones significantly minimizes the risk of maternal and foetal complications and makes it possible that the pregnancy may be carried to term without severe complications.

\section{Funding: No funding sources}

Conflict of interest: None declared

Ethical approval: The study was approved by the Institutional Ethics Committee

\section{REFERENCES}

1. Akhter SN, Tarannum R, Kabir MS. Pregnancy in overt and subclinical hypothyroidism and its fetomaternal outcome. Med Today. 2014;25(2).
2. Sahu MT, Das V, Mittal S, Aggarwal A, Sahu M. overt and subclinical hypothyroid dysfunction among Indian pregnant women and its effect on maternal and foetal outcome. Arch Gynecol Obstet. 2010;281(2):215-20.

3. Ajmani SN, Aggarwal D, Bhatia P, Sharma M, Sarabhai V, Paul M. Prevalence of overt and subclinical thyroid dysfunction among pregnant women and its effect on maternal and foetal outcome. J Obstet Gynecol India. 2014;64(2):10510 .

4. Nirmala CV. Maternal outcome of hypothyroidism in pregnancy- a south Indian perspective. Am J Clin Med Res. 2014;2(2):47-50.

5. Goel P, Radotra A, Devi K, Malhotra S, Aggarwal A, Huria A. Maternal and perinatal outcome in pregnancy with hypothyroidism. Indian J Med Sci. 2005;59 (3):116-7.

6. Cleary-Goldman J, Malone FD, Lambert-Messerlain G, Sullivan L, Canick J, Porter TF, et al. Maternal thyroid hypo function and pregnancy outcome. Obstet Gynecol. 2008;112(1):85-92.

7. Casey BM, Dashe JS, Wells CE, McIntre DD, Byrd W, Leveno KJ, et al. Subclinical hypothyroidism and pregnancy outcomes. Obstet Gynecol. 2005;105(2):239-45.

8. Allan WC, Haddow JE, Palomaki GE, Williams J R, Mitchell ML, Hermos RJ, et al. Maternal thyroid deficiency and pregnancy complications implications for population screening. J Med Screen. 2000;7(3):127-30.

9. Stagnaro-Green A, Abalovich M, Alexander E, Azizi F, Mestman J, Negro R, et al. Guidelines of the American Thyroid Association for the diagnosis and management of thyroid disease during pregnancy and postpartum. Thyroid Off J Am Thyroid Association. 2011;21(10):1081-125.

10. Basnet P, Aggarwal N, Suri V, Dutta P, Mukhopadhyay K. Comparison of Maternal and perinatal outcome in pregnant women with hypothyroidism diagnosed before conception with hypothyroidism diagnosed during pregnancy Univers Coll Med Sci. 2014;2(2).

Cite this article as: Prasad DR, Nair NV, Deepika $\mathrm{K}$. A descriptive study of the prevalence of hypothyroidism among antenatal women and foetal outcome in treated hypothyroid women. Int $\mathbf{J}$ Reprod Contracept Obstet Gynecol 2016;5:1892-6. 